\title{
WELD REPAIR OF CRACKED BEAMS AND RESIDUAL FATIGUE LIFE
}

\author{
By Kentaro YAMADA*, Yoshinaga SAKAI**, Akimasa KONDO*** \\ and Yoichi KIKUCHF****
}

\begin{abstract}
Fatigue cracks often initiate at as-welded toe of various attachments where stress concentration is high. Bending fatigue tests were carried out on two beams with welded cover plates and gussets. About forty fatigue cracks were observed, when the cracked parts were successively repaired with stopholes and splice plates. The fatigue test results were compared with previous test data. The cracked beams were further repaired with groove welds and fatigue tests were continued. Fatigue cracks initiated and propagated from weld defects near the end of the attachments. Fatigue life of repaired parts was somewhat longer than that of as-welded one due to grinding the weld toes after weld repair.

Keyword: fatigue test, crack, weld repair, beam, attachment
\end{abstract}

\section{INTRODUCTION}

Railway bridges and crane runway girders often experienced fatigue cracking. Recent discovery of cracks in structural details in highway bridges, possibly due to a large number of overloads, enhanced research needs on methods of adequate repair and strengthening ${ }^{1) 2}$. When crack is found in a structural member of an existing bridge, the following repair and strengthening methods are often carried out.

(1) The crack is examined and a stophole is drilled at the leading edge of the crack to arrest the further crack propagation. Sometimes, the stophole itself becomes the sufficient crack arrester.

(2) Groove is made along the line of the crack, and the crack is repaired by the complete penetration groove weld. In order to achieve better fatigue resistance, weld reinforcement is ground flush.

(3) After repaired by a stophole and/or groove weld, cracked part is often strengthened with high strength bolted splice plates. When fatigue cracking is prone to occur, the strengthening is also carried out for precaution. An alternative way to strengthen the cracked parts is to fillet-weld splice plates.

(4) If possible, structures are modified in order to remove the structural deficiency which causes fatigue cracking. For example, rectangular gussets welded to tension flange are ground to have smooth transition at the end of the gussets, or they are shifted to web where bending stresses are less than the tension flange.

Feasibility of these repair and strengthening procedures depend on working condition at the site, cost of the works and the reliability of the repaired details. Engineers often decide individually what seems the

* Member of JSCE, Ph. D., Asso. Prof., Dept. of Civil Eng., Nagoya University, (Chikusaku, Nagoya)

** Member of JSCE, M. Sc., Research Laboratory, Topy Industry, Ltd. (Toyohashi)

*** Member of JSCE, Dr. Eng., Asst. Prof., Dept. of Civil Eng., Meijo University (Tenpakuku, Nagoya)

**** Member of JSCE, Dr. Eng., Prof., Dept. of Civil Eng., Chubu University (Kasugai) 
best rehabilitation procedure to the particular structure ${ }^{9)}$.

Among the several repaired procedures, the full penetration groove repair weld is frequently used at site, because the cracked member regains the continuity once damaged by fatigue cracking. The more the research and the experience on the field welding are gained, the more the groove weld repair seems to be employed. However, the fatigue behavior of members with the repair weld is not yet clarified. More research is needed to evaluate the effectiveness of the repair weld.

In this study, fatigue tests were carried out on two large size welded beams with gussets and cover plates welded to tension flanges to observe fatigue behavior of these details in as-welded condition. Fatigue cracked parts were then repaired by groove welds and retested. Effects of qualification of welders and the sequence of welds on fatigue behavior of repaired details were also discussed. These repaired details were examined by ultrasonic test and X-ray radiographic test prior to the fatigue tests.

\section{FATIGUE TEST}

\section{(1) Fabrication of test beams}

Two fatigue test beams of $4 \mathrm{~m}$ span, A 1 and A 2, as shown in Fig. 1, were fabricated of JIS SM 50 A steel (specified yield point of $314 \mathrm{MPa}$ and ultimate strength of $490 \mathrm{MPa}$ ). Chemical composition and mechanical properties of tension flange is shown in Table 1. The following attachments were welded manually to the tension flange and the web.

(a) G-type Gussets : Plates of $50 \times 10 \times 200 \mathrm{~mm}$ groove-welded horizontally to both sides of the tension flanges of $300 \mathrm{~mm}$ wide. The groove was 45 degree. Six G-type gussets were welded to A 1 beam and four to $\mathrm{A} 2$ beam.

(b) T-type Gussets: Plates of $100 \times 10 \times 200 \mathrm{~mm}$ fillet-welded transversely to both sides of the tension flanges. Four T-type gussets were welded to both $\mathrm{A} 1$ and $\mathrm{A} 2$ beams.

(c) GW-type Gussets : Plates of $100 \times 10 \times 200 \mathrm{~mm}$ fillet-welded to web. Two GW-type gussets were welded to $\mathrm{A} 1$ beam and one to $\mathrm{A} 2$ beam.

(d) Cover Plate: A plate of $200 \times 10 \times 400 \mathrm{~mm}$ fillet-welded to the center of the tension flange of A 2 beam. All welds were made manually by covered electrodes of $3.2 \mathrm{~mm}$ diameter corresponding to JIS Z 3212-D 5016, and were left as-welded.

\section{(2) Fatigue test}

Three points bending fatigue tests were carried out with servo-hydraulic testing machine of $350 \mathrm{kN}$, as shown in Fig. 2. Load ratio was 0.1 and loading speed was about $1.6 \mathrm{~Hz}$. Copper wire of $0.1 \mathrm{~mm}$ diameter was glued to each toe of the weld and $10 \mathrm{~mm}$ away from the toe. They were wired to a buzzer, which was triggered when fatigue crack cut the copper wire. The test beams were also monitored every 1 or 2 hours by naked eyes.

When fatigue crack initiated and propagated to a size of about $10 \mathrm{~mm}$, a stophole was drilled at the

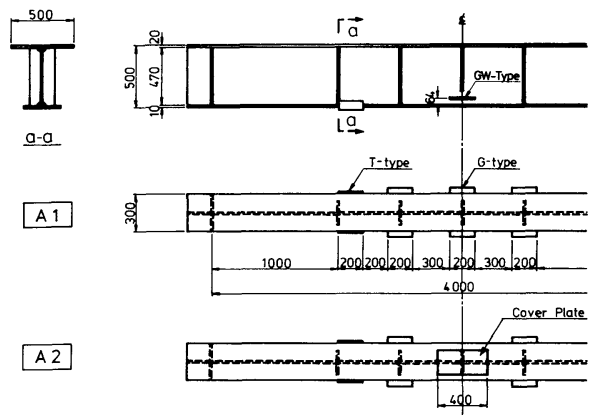

Fig. 1 Bending fatigue test beams with welded gussets and cover plates.

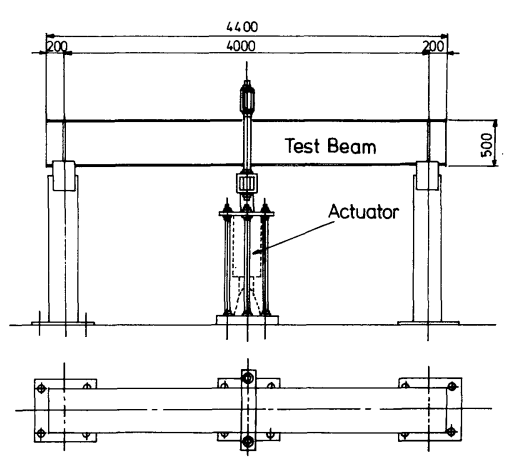

Fig. 2 Fatigue test set-up. 
Table 1 Chemical composition and mechanical properties of steel.

\begin{tabular}{|c|c|c|c|c|c|c|c|}
\hline $\begin{array}{l}\text { Steel } \\
\text { Lower } \\
\text { Flange }\end{array}$ & $\begin{array}{l}\text { Yield } \\
\text { Point } \\
\text { (MPa) }\end{array}$ & $\begin{array}{c}\text { Tensile } \\
\text { Strength } \\
\text { (MPa) }\end{array}$ & $\begin{array}{l}\text { Elonga- } \\
\text { tion } \\
\left(\begin{array}{l}\text { in } \\
(\%)\end{array}\right.\end{array}$ & & $\begin{array}{r}\text { ical } \\
S i \\
x 100\end{array}$ & $\begin{array}{c}\text { Composition } \\
M_{n} \times \\
\times 100 \times 1000\end{array}$ & $\begin{array}{l}(\%) \\
S \\
\times 1000\end{array}$ \\
\hline SM50A & 373 & 520 & 26 & 16 & 29 & $132 \quad 13$ & 5 \\
\hline
\end{tabular}

leading edge of the crack. The number of cycle corresponding to this crack size was assumed as the fatigue life, $N_{f}$.

The stophole was further strengthened by a pair of splice plates bolted from both sides of the cracked details. Fatigue tests were then continued to observe fatigue cracking from other details. Practically all gussetted details exhibited fatigue cracking. Photo 1 shows the tension flange of the test beam where high strength-bolted splices were attached to stiffen the cracked parts.

\section{FATIGUE TEST RESULTS OF AS-WELDED DETAILS}

\section{(1) Fatigue crack initiation and propagation}

The Al beam was subjected to load range of $P_{r}=192 \mathrm{kN}$ (stress range at the midspan was $\sigma_{r}=98 \mathrm{MPa}$ ). All ends of the gussets welded to tension flange successively exhibited fatigue cracking at the toes of the welds and the test was discontinued at 2 million cycles. The A 2 beam was tested at $P_{r}=212 \mathrm{kN}\left(\sigma_{r}=\right.$ $108 \mathrm{MPa}$ ) and the fatigue crackings were observed at 14 toes of the gusset ends and both sides of the cover plates. The fatigue test was discontinued at 1.1 million cycles. No fatigue cracking was observed at the gussets welded to the web (GW-type gussets).

(2) Fatigue strength of as-welded gussets

G-type Gussets : Fatigue test results of $200 \mathrm{~mm}$ long gussets welded to tension flanges are plotted in Fig. 3. Also plotted are the fatigue test data of tensile plates of $200 \mathrm{~mm}$ wide with the as-welded gussets of $200 \mathrm{~mm}$ long ${ }^{3)}$. The mean $S-N$ diagram and the standard deviation, $s$, were computed from total of 26 data, as follows.

$\log N_{f}=12.699-3.648 \log \sigma_{r} \quad s=0.123$

The mean $S-N$ diagram and the confidence limits plotted two standard deviations away from the mean are shown by solid lines in Fig. 3.

The fatigue strength of this type of gussets is known to be low, and the ends of the gussets are normally specified to be ground to the radius of $r \geqq 40 \mathrm{~mm}$ for the railway bridges in Japan ${ }^{7}$ in order to avoid possibility of fatigue cracking. For steel structures other than railway bridges, as-welded gussets are often used, and the JSSC recommendation for fatigue design specified this detail as detail class $\mathrm{F}^{4)}$. All

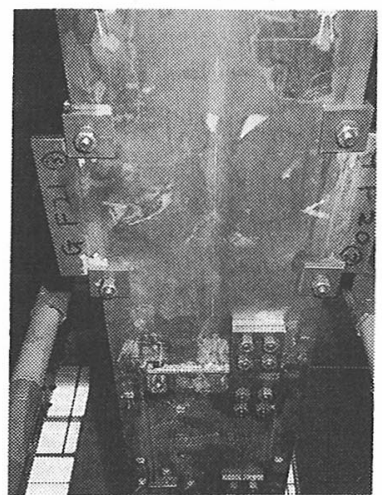

Photo 1 Fatigue cracked tension flange looking underneath. Stopholes drilled at leading edge of cracks are stiffened with high strength bolted splices.

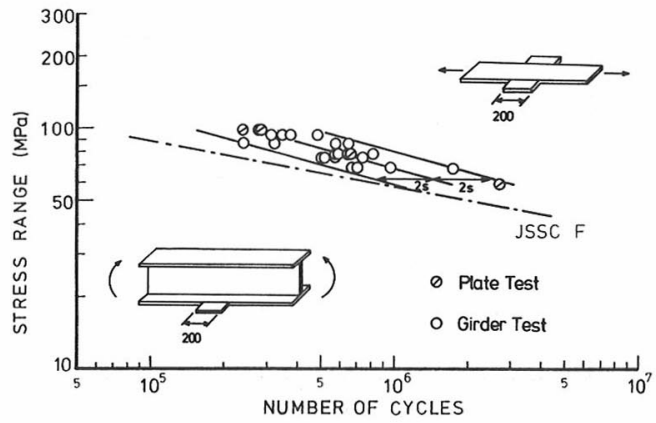

Fig. 3 Fatigue test results of beams with groove welded gussets of $200 \mathrm{~mm}$ long (G). 
test data seems to satisfy the allowable stress range, as shown in Fig. 3 .

T-type Gussets : Fatigue test results of $200 \mathrm{~mm}$ gussets welded transversely to tension flange are plotted in Fig. 4. Also plotted the test data previously obtained for the same type of gussets welded to tensile plates ${ }^{3)}$. The mean $S-N$ diagram and the confidence limits are also plotted in Fig. 4 . They are determined from total of 19 data, as follows.

$$
\log N_{f}=12.197-3.540 \log \sigma_{r} \quad s=0.128
$$

The stress concentration factor at the end of the T-type gusset is higher than that of the G-type gussets, when the length of the gussets is the same ${ }^{3}$. Therefore, fatigue strength of $T$-type gusset is lower than that of G-type gusset. The detail is not specified in the JSSC recommendation for fatigue design. If one applies the detail class $\mathrm{F}$ for this detail, some data fails to satisfy the allowable stress range, as shown in Fig. 4. It implies that the allowable stress range of this detail ought to be lowered to, for example, detail class G.

GW-type Gussets : No fatigue cracking was observed at the end of the gussets welded to the web, even after the additional fatigue tests which were carried out after weld repair. The runout data is plotted with an arrow in Fig. 5, along with the previous test data of the same type of details ${ }^{5}$. The present test data seems to show longer fatigue life compared with the previous test data. This may be due to the good weld toe shape which is favorable to fatigue resistance. The data satisfy the allowable stress range of detail class $\mathrm{E}$ of the JSSC recommendation for fatigue design.

Cover Plate: The as-welded cover plate showed four independent fatigue crackings at the toes of the end fillet welds perpendicular to the applied stresses. The cracks propagated into the flange plate and then to the web. The test data is plotted in Fig. 6 with the test data generated at Lehigh University ${ }^{6}$. The cover plate in the present test was $400 \mathrm{~mm}$ long and it showed an equivalent fatigue life as the Lehigh data, provided that the cover plate length of Lehigh data was over $1000 \mathrm{~mm}$. The detail is classified into detail class $\mathrm{F}$ according to the JSSC recommendation for fatigue design. The data satisfied the allowable stress range, as shown in Fig. 6.

\section{WELD REPAIR OF CRACKS}

\section{(1) Groove weld repair procedure}

After the fatigue tests in as-welded condition, the test beams had a number of fatigue crackings in the tension flange. These fatigue cracks were about $20 \mathrm{~mm}$ long and stopholes were drilled at the crack tips. Prior to the weld repair, an additional hole of $10 \mathrm{~mm}$ diameter was drilled some distance away from the edge of the flange, and a slit was made by gas cutting. This simulates as if a fatigue

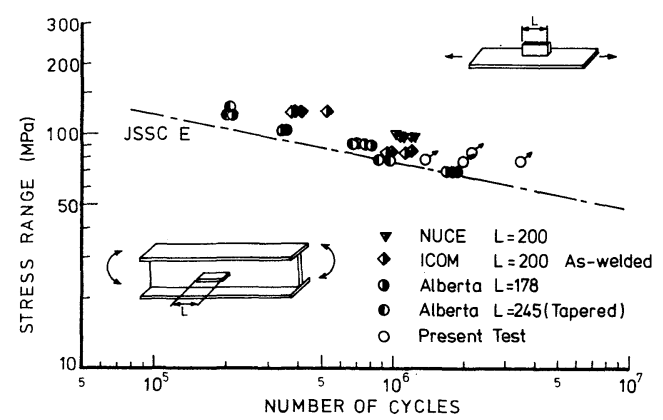

Fig. 5 Fatigue test results of a beam with gussets welded to web $(\mathrm{GW})$.

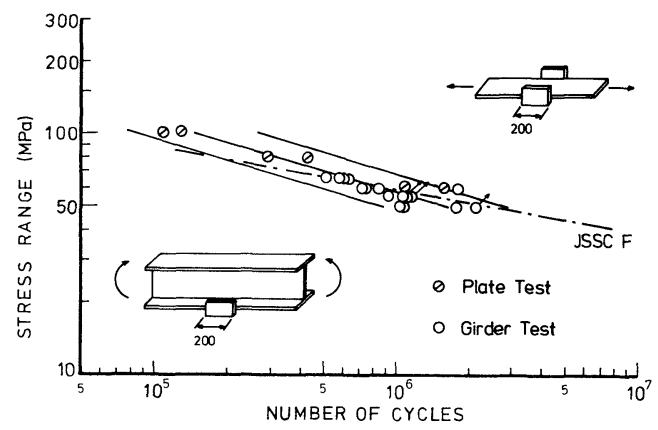

Fig. 4 Fatigue test results of beams with fillet welded gussets of $200 \mathrm{~mm}$ long $(\mathrm{T})$.

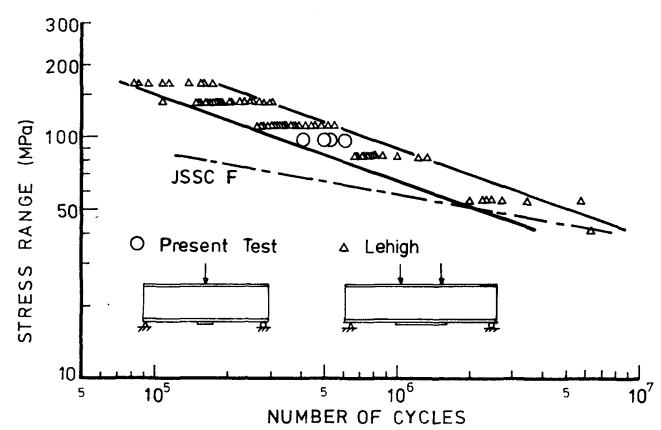

Fig. 6 Fatigue test results of beams with a welded cover plate of $400 \mathrm{~mm}$ long. 
crack becomes so long that it can be detected even by eyes. The repair procedure was as follows:

G-type Gussets : As shown in Fig. 7, an original crack was extended to $100 \mathrm{~mm}$ long by drilling and gas cutting. First, groove were made on both sides of the plates by arc air gouging in flat position. It was groove-welded in four or five passes. At the drilled holes, a penny shape disc of $3 \mathrm{~mm}$ thick and $8 \mathrm{~mm}$ diameter was tack-welded in order to avoid the melting down of the weld metal.

The groove weld was then back chipped from underneath. Dye check was applied to ensure no weld crack was left at the weld, before groove weld was made in the overhead position. The reason to why the final repair weld was made in the overhead position was to simulate the unfavorable site condition where the weld repair must be made from underneath. This welding position is believed to cause more weld defects than the flat position. The weld reinforcement was then ground flush, and the end weld of the gusset was ground to the radius of about $20 \mathrm{~mm}$.

T-type Gussets: For the T-type gussets, a stophole was drilled at about $30 \mathrm{~mm}$, and a slit was made to simulate a crack of $30 \mathrm{~mm}$ long. The repair procedure by groove weld was carried out in the same manner as the G-type gussets. However, the weld sequence was reversed, that is the final groove weld was placed in the flat position. The weld reinforcement and the gusset end was also ground.

Cover Plate: Fatigue cracks at the end of the cover plate of A 2 beam propagated through the tension flange and penetrated into the web. As shown in Fig. 8, the weld repair was made first on one side of the web and flange by arc air gouging and groove-welding. Then the other side was repaired. The flange plate was back-chipped from underneath, and groove welded in the overhead position. The weld reinforcement was removed by grinding, and the welds at the cover plate ends was ground to about $20 \mathrm{~mm}$ radius.

\section{(2) Welding}

All repair welds were made manually using the covered electrodes of $3.2 \mathrm{~mm}$ diameter which is conformed to JIS Z 3212-D 5016. An engine driven welder was used to simulate the field welding. The work was carried out in a factory. The repaired beams were placed about $800 \mathrm{~mm}$ above ground, and it
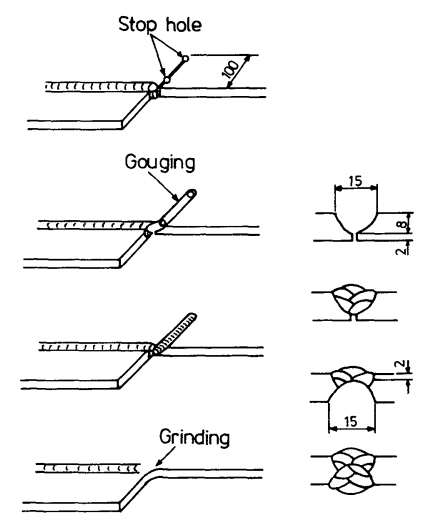

Fig. 7 Repair procedure of crack at gusset end by groove weld.

Table 2 Qualification of welders.

\begin{tabular}{|c|l|l|}
\hline Welder & Experience & Qualification \\
\hline$A$ & 10 -year & $\begin{array}{l}\text { A-2F,A-2V } \\
\text { SA-2F, SA-2V,SA-20 } \\
\text { SA-3F }\end{array}$ \\
\hline$B$ & 4 -year & $\begin{array}{l}\text { A-2F,A-2V } \\
\text { SA-2F,SA-2V }\end{array}$ \\
\hline
\end{tabular}
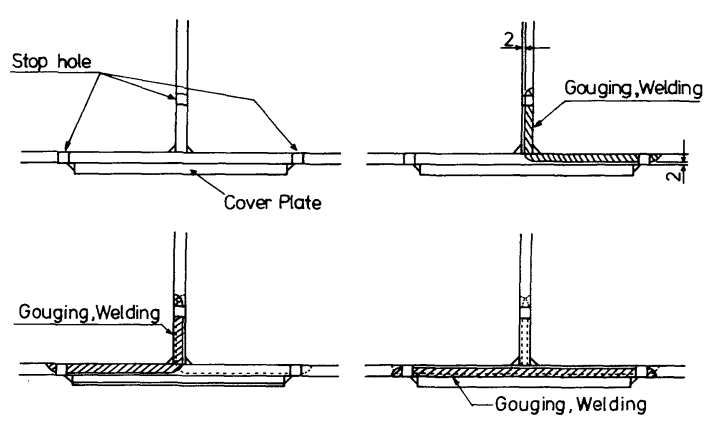

Fig. 8 Repair procedure of crack at cover plate end by groove weld.

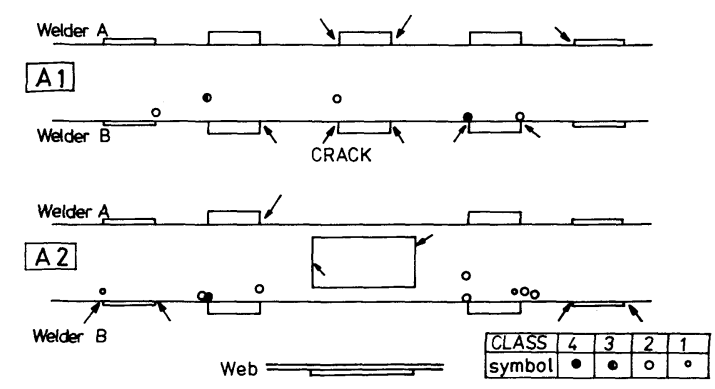

Fig. 9 Non-destructive test results at the groove weld repair by ultrasonic test. 
resulted in an unfavorable welding condition especially when the welds were to be made in the overhead position. The repair welds were made by two welders, namely the welders A and B. Each welder worked on one side of the tension flange, as shown in Fig. 9, to see the effect of welder's qualification on the quality of the repair welds. As listed in Table 2, the welder A had about 10 years of experience and engaged mainly to welding works. The welder B, on the contrary, had about 4 years of experience and did not possess the qualification on the welding in the overhead position.

\section{(3) Non destructive testing}

In order to verify the weld quality of the groove weld repair, ultrasonic test and X-ray radiographic test were carried out based on JIS Z 3060 and JIS Z 3104, respectively. The test results are shown in Figs. 9 and 10. The arrow indicates that fatigue cracking was observed when fatigue tests were carried out after the repair. The welders A and B indicate who made the repair welds. Numerous weld defects were detected in the repair weld due to the fact that the welding condition was relatively unfavorable. No additional repair was made, even though large defects were detected by the non-destructive tests.

Type of Weld Defects : The X-ray radiographic test revealed that blowholes (BH) frequently existed in many repair welds while a few slag inclusion (SI) and lack of fusion (LF) were observed. These weld defects were mainly observed at or near the drilled holes and near the edge of the flange plates. It implies that the plug welding of the drilled holes and the start-stop position tend to cause weld defects.

Classification of Weld Defects: Majority of the repaired welds were classified into class 3 or class 4 by the X-ray radiographic test. The ultrasonic test, however, failed to detect such defects and only a few were classified into class 3 or 4 . It may be due to the fact that the ultrasonic test had some difficulty to scan near the end of the gussets where weld defects were significant. Both tests showed that the experienced welder introduced less weld defects than the unexperienced one. This was especially significant on the repair weld of $\mathrm{T}$-type gussets.

\section{FATIGUE TEST RESULTS AFTER REPAIR WELD}

\section{(1) Fatigue test}

The bending fatigue tests of the beams after repair weld were carried out in the same manner as the as-welded ones. The beams were monitored periodically and the fatigue life, $N_{f}$, was defined when a crack propagated to about $10 \mathrm{~mm}$ long. When fatigue crack became about $20 \mathrm{~mm}$ long, a stophole was drilled and stiffened by high strength bolted splices.

For A 1 beam, load range of $P_{r}=251 \mathrm{kN}$ was applied which resulted in the stress range $\sigma_{r}$ of $128 \mathrm{MPa}$ at the span center. Eight fatigue crackings were observed successively after 2.21 million cycles of loading. The A 2 beam was first subjected to $P_{r}=212 \mathrm{kN}\left(\sigma_{r}=108 \mathrm{MPa}\right)$ and four cracks were found after 1.44 million cycles of loading. Then the applied load was increased to $P_{r}=251 \mathrm{kN}\left(\sigma_{r}=128 \mathrm{MPa}\right)$ and three other cracks were observed.

\section{(2) Fatigue strength of repair welds}

The fatigue crackings were observed at the details indicated by arrows in Fig. 9. These details were cut out after the test and the fracture surfaces were examined. The other details which showed no cracking were examined again by the ultrasonic test and X-ray radiographic test, but no additional fatigue cracking was detected. 
G-type Gussets : Eight out of 20 repair welds exhibited fatigue cracking. The fatigue crack initiated from the fillet of the gusset ends and propagated in the direction perpendicular to the principal stress. Typical fatigue fracture surfaces are shown in Photo 2. Photo 2 a) shows a fracture surface with few weld defect. Fatigue cracking seems to occur from grinding marks at the fillet, and it showed the longest fatigue life among the failed details. In Photo $2 \mathrm{~b}$ ), blowholes exist near the fillet, and the fatigue crack initiated from these blowholes. It resulted about an average fatigue life of the failed data. The most harmful to the fatigue resistance was large and numerous defects near the fillet, as shown in Photo $2 \mathrm{c}$ ). Fatigue cracking seems to occur from these defects and coalesced to a large crack. It showed the shortest fatigue life.

Fatigue test results of G-type gussets are plotted in Fig.11. All test data was found to have longer fatigue life than the as-welded ones shown by a confidence interval. It may be because the ends of the gussets were ground to the radius of about $20 \mathrm{~mm}$ which eliminated high stress concentration at the weld toes. It implies that the weld defects observed in the repair welds were less harmful than the stress concentration at the weld toes of the gusset ends. Therefore, the repair welds described here are acceptable to repair fatigue crack and to prolong the fatigue life.

Compared to the previous test data of the gussets with ground ends of 20 to $30 \mathrm{~mm}$ radius $^{7)}$, it revealed that the present test data showed somewhat shorter fatigue life. It may be due to the weld defects near the fillet, which seems to trigger early fatigue cracking and thus reduce fatigue life.

The JSSC recommendation for fatigue design classifies the ground ends of over $20 \mathrm{~mm}$ radius into detail class $\mathrm{D}^{4}$. When repair weld is not subjected to an appropriate non-destructive testing, the fatigue life may not satisfy this allowable stress range. In these cases, it may be safe to lower the allowable stress range of the repair weld, for example, to the detail class $\mathrm{F}$ for the as-welded gussets.

T-type Gussets : Five of 16 T-type gussets developed fatigue crackings. The cracks initiated and

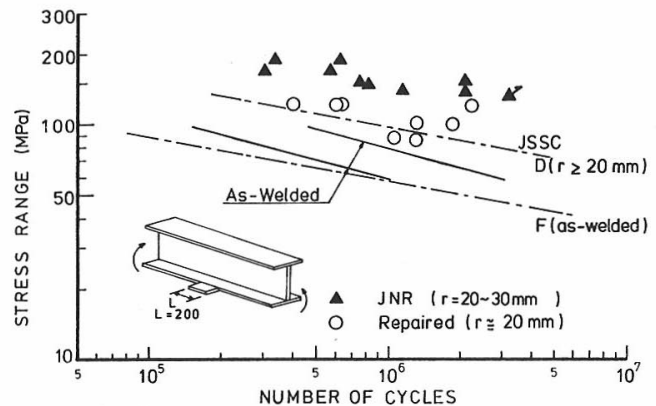

Fig. 11 Fatigue test results of beams with gussets of 200 $\mathrm{mm}$ long (G) after weld repair.
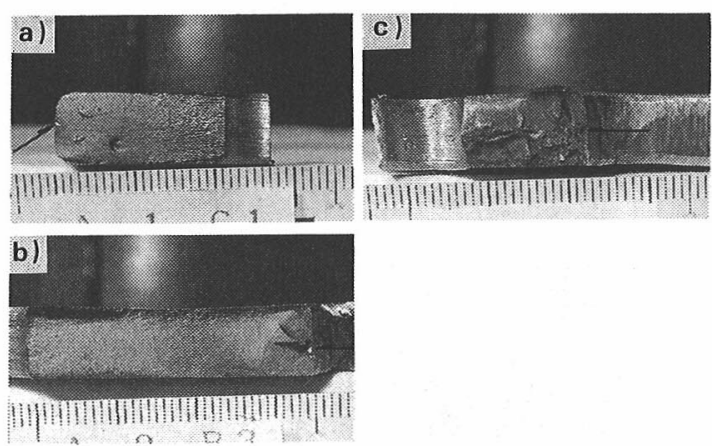

Photo 2 Typical fatigue fracture surfaces of groove welded gusset ends $(G)$. Weld defects were visible on the surfaces.

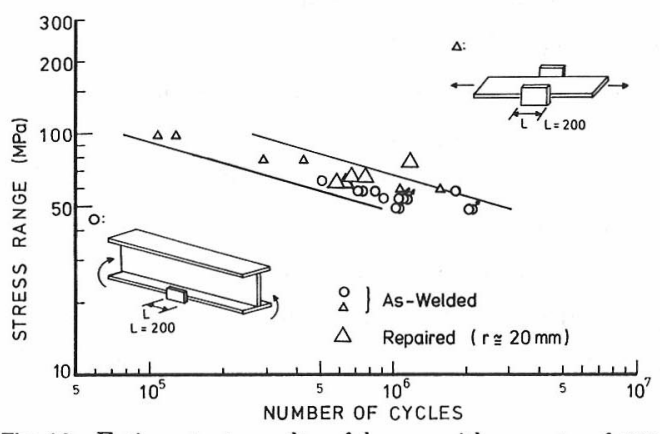

Fig. 12 Fatigue test results of beams with gussets of 200 $\mathrm{mm}$ long ( $\mathrm{T})$ after weld repair.
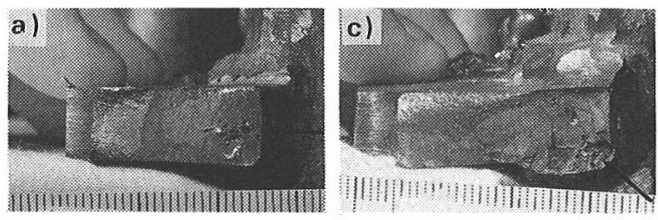

b)

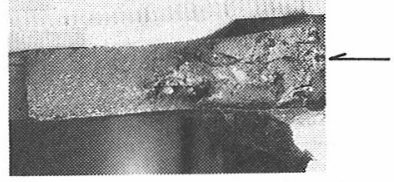

Photo 3 Typical fatigue fracture surfaces of fillet welded gusset ends (T). Numerous weld defects were visible near the end of gussets (left). 
propagated from the weld defects near the fillet. Typical fracture surfaces are shown in Photo 3. A number of weld defects such as blowholes, slag inclusion and lack of fusion can be seen on the fracture surfaces, as shown in Photos 3 a) and 3 b). Fatigue cracks initiated from these weld defects, and it resulted relatively short fatigue life. In Photo $3 \mathrm{c}$ ), a number of small and spherical defects can be seen near the fillet, where the fatigue crack initiated. The fatigue life of this detail was one of the longest among the failed T-type gussets.

Fatigue test results of the T-type gussets with repair welds are plotted in Fig. 12, where the as-welded data is indicated by two solid lines corresponding to the confidence interval. The present test data of the repair welds showed approximately the same fatigue life as the as-welded gussets, even though the gusset ends were ground.

As shown in Photo 3, relatively large weld defects were introduced near the fillet of the T-type gussets, because of the unfavorable welding condition. The stress concentration due to the gussets was superimposed to these weld defects, and it yielded to low fatigue strength, despite the ground fillet at the end of the gussets. This detail can be classified into detail class $G$, if it is as-welded. It may be appropriate to use the same detail class for the repair weld, provided that the gusset ends are ground to achieve smooth transition.

Cover Plate: Photo 4 a) shows the fracture surface of the cover plate ends, where a crack of $4 \mathrm{~mm}$ long was observed at 630000 cycles. Several cracks initiated at the transition from the flange to cover plate, and propagated in semi-elliptical shape. The radius of the fillet of this side was relatively small and the grinding marks were left on the surface. This may cause early fatigue cracking. The fracture surface revealed that sizable weld defects existed at the junction of the flange and the web, where the repair weld was placed from three sides. These weld defects, however, were not the major crack initiation points. Photo 4 b) shows the fatigue cracking occurred from the plug welding of the stophole near the end of the transverse fillet weld. A few cracks initiated in the different plane and joined together as they propagated.

Fatigue test results of the cover plates after repair weld are plotted in Fig. 13. Also plotted are the confidence interval of the as-welded cover plates tested at Lehigh University ${ }^{6}$ and the test data of the cover plated beams with tapered end welds tested at University of Maryland ${ }^{8)}$. The data of the repair weld showed an equivalent or longer fatigue life compared to the as-welded ones, owing to the ground end welds. Especially one side of the cover plate resisted 1. 44 million cycles of loading, and additional 1.16 million cycles of higher loading before fatigue cracking was observed at the plug weld of the stopholes. It implies that the present weld repair procedure was satisfactory to repair cracks from the cover plate ends. The

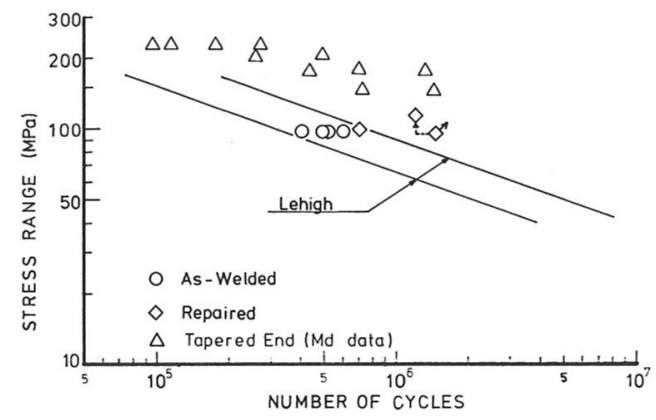

Fig. 13 Fatigue test results of cover plates after weld repair.
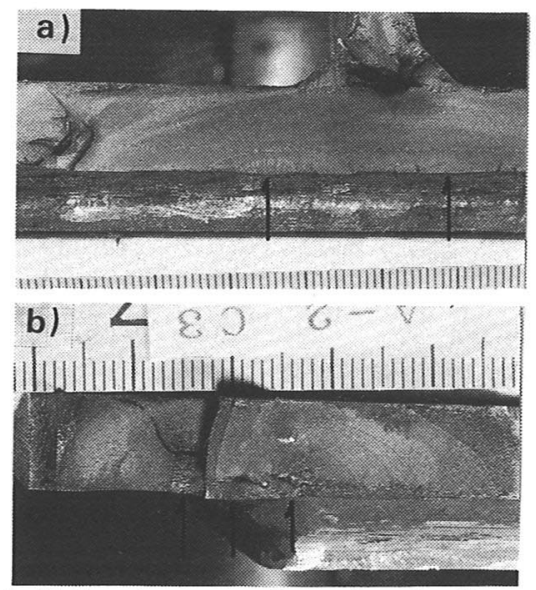

Photo 4 Fatigue fracture surfaces of tension flanges at the end of cover plates. Repair was made by groove weld. 
data of the repair weld showed somewhat lower fatigue strength than the cover plated details with tapered end welds. The weld defects introduced by the repair weld may have caused the reduction of fatigue strength. Therefore, it may be safe to use the same allowable stress ranges for the repair weld with ground end weld of cover plate, although the cover plates with tapered end welds to $1: 2$ was classified into detail class $\mathrm{C}$ in the JSSC recommendation ${ }^{4)}$.

\section{(3) Classification of weld defects and fatigue strength}

The X-ray radiographic tests seem to reveal the weld defects near the edge of the tension flange, from which most of the fatigue crackings occurred. However, the classification of the repair weld was decided not only the area near the fillets, which was found critical to the fatigue strength, but also the entire repair weld. The majority of the repair welds were classified into class 3 or 4 , and the calssification could not be correlated with the fatigue life. Therefore, the classification employed here was found insufficient to indicate fatigue resistance of the repair weld of the gussetted details.

The ultrasonic test failed to detect the weld defects near the fillets which were influential to the fatigue resistance. When this test is carried out on the repair welds, care must be taken to ensure the soundness of the welds especially where stress concentration affects.

\section{SUMMARY OF FINDINGS}

Fatigue tests of two beams with welded cover plates and gussets were carried out and the basic fatigue strength of as-welded detail was determined. Fatigue cracked details were then repaired by groove welds simulating the repair weld at site. The repair welds were made by two welders in an unfavorable weld position to simulate the field welding. These repair welds were monitored by the ultrasonic tests and the $\mathrm{X}$-ray radiographic tests. The beams were retested and the fatigue resistance of the repair weld was examined. The followings summarize the results.

(1) The beam tests revealed that the gussets welded to the tension flange tips (G-type gussets) and the gussets welded transversely to the tension flange tips (T-type gussets) showed an equivalent fatigue strength as those welded to tensile plates.

(2) It seems appropriate to use the allowable stress range of detail class F for the G-type gussets, as was specified by the JSSC recommendation for fatigue design. For T-type gussets, the detail class G was appropriate.

(3) The as-welded cover plate of $400 \mathrm{~mm}$ long showed comparable fatigue life as those tested as Lehigh University, and it was confirmed that the detail class $F$ was appropriate.

(4) It was found that weld defects such as blowholes and slag inclusion were prone to occur at the plug welding of the stopholes and at the stop position near the edge of the flange.

(5) Fatigue cracks initiated from the weld defects near the fillet at the end of the gussets.

(6) Since the repair weld was made in an unfavorable welding condition to simulate the field welding, majority of the repair weld was classified into class 4 by the X-ray radiographic tests. The ultrasonic test showed some difficulties to detect the weld defects near the fillet. Care must be taken to use this method to the repair welds of the gussetted details.

(7) Since all repair welds were ground to achieve smooth transition to radius of $20 \mathrm{~mm}$, the fatigue life of the repair welds was an equivalent or longer than those of the as-welded ones. It implies that the repair weld procedure employed here may be satisfactory, if one expects the same fatigue life as the as-welded ones.

\section{ACKNOWLEDGEMENTS}

This study was supported in part by the Grant-in Aid for Scientific Research from the Japanese Ministry of Education, Science and Culture. The fatigue tests were carried out in the Department of Civil Engineering of Nagoya University. The authors are grateful for Messrs. E. Matsui, M. Miyake and M. 
Togasaki for their invaluable assistance.

\section{REFERENCES}

1) Abe, H., Taniguchi, N. and Abe, M. : Fatigue Problems in Steel Railway Bridges and Repair and Rehabilitation, The Bridge and Foundation Engineering, Aug. 1983 (in Japanese).

2) Nishikawa, K. : Fatigue Problems in Highway Bridges and Repair and Rehabilitation, The Bridge and Foundation Engineering, Aug. 1983 (in Japanese).

3) Yamada, K., Sakai, Y. and Kikuchi, Y. : Fatigue of Tensile Plates with Gussets and Stop Holes as Crack Arrest, Proc. of JSCE, No. 341, Jan. 1984 (in Japanese).

4) Japan Society of Steel Construction : JSSC Recommendation for Fatigue Design, JSSC, Vol. 10, No. 101, May. 1975 (in Japanese).

5) Yamada, K., Mitsugi, Y. and Kondo, A. : Fatigue Strength of Gussets Welded to Tension Members and Allowable Stresses, Journal of Structural Engineering, Vol. 32 A, March, 1986 (in Japanese).

6) Fisher, J. W. et al. : Effect of Weldments on the Fatigue Strength of Steel Beams, NCHRP Report 102, National Research Council, 1970.

7) The Japan Society of Civil Engineers : Design Specifications of Japanese National Railways, May, 1983 (in Japanese).

8) Yamada, K. and Albrecht, P. : Fatigue Behavior of Two Flange Details, Proc. of ASCE, Vol. 103, No. ST 4, April, 1977.

9) Yamada, K. and Kondo, A. : Fatigue Behavior of Repaired Members with Crack, Proc. of JSCE, No. 368/ I -5, April, 1986 (in Japanese).

(Received April 3 1986) 